\title{
Reduced test-day milk fat percentage in cows diagnosed with claw horn lesions during routine claw trimming
}

\author{
M. van Straten, ${ }^{*}{ }^{1}{ }^{1}$ I. Siani, $\neq$ and D. Bar§ \\ *Hachaklait, Mutual Society for Veterinary Services, POB 3039, Caesarea Industrial Park 38900, Israel \\ †Koret School of Veterinary Medicine, Faculty of Agriculture, Hebrew University of Jerusalem, POB 12, Rechovot 76100, Israel \\ $\ddagger$ A.A. Hoof Trimming, Yachini 64, 79170, Israel \\ §SCR Engineers Ltd., Natanya, Israel
}

\begin{abstract}
The objective of this study was to investigate whether cows diagnosed with claw horn lesions during routine claw trimming had an altered milk fat percentage on test days preceding the diagnosis, compared with cows without such lesions. Data included date of trimming, cow number, type, and location of claw lesions recorded by a professional claw trimmer during routine trimming sessions on 11 commercial dairy farms, and monthly test-day data. Recordings from 4,381 cows were included in the analysis. Three hundred seventy-two (8.5\%) cows were diagnosed with at least one claw lesion. One hundred ninety-five $(4.4 \%)$ cows were classified as cases of laminitis and 169 cows (3.9\%) were classified as cases of infectious claw diseases. Average test-day milk fat percentage was estimated from monthly test-day data using a mixed model with a random farm effect and a marginal effect for repeated measurements. Estimated milk fat percentage of cows classified as cases of laminitis on the day of claw trimming was 0.17 and $0.22 \%$ less than that of cows with either no claw lesion or those with an infectious claw disease, on test days occurring 2 and 5 mo before claw trimming, respectively. To the best of our knowledge, decreased test-day milk fat percentage in dairy cows diagnosed with claw horn lesions has not been described. Because decreased milk fat and claw horn lesions have both been associated with subacute ruminal acidosis, it is plausible that subacute ruminal acidosis played a role in the association we found. A prospective study with a greater frequency of claw examinations would be necessary to help clarify these associations. Our findings indicate that test-day milk fat might be useful as a tool for monitoring cows and farms at risk for claw horn lesions.
\end{abstract}

Key words: laminitis, dairy cow, milk fat

Received September 24, 2010.

Accepted January 10, 2011.

${ }^{1}$ Corresponding author: chkl351@netvision.net.il

\section{INTRODUCTION}

Traditionally, the underlying aseptic pathological condition affecting the bovine claw and playing an important role in the etiology of solar hemorrhages, solar ulcers, and white line disease has been referred to as laminitis (Vermunt, 2007). It has been assumed that the etiology of bovine laminitis is analogous to that of equine laminitis, following the same stages described in the latter species. These stages are a) disturbance in the microcirculation of the corium of the claw with subsequent degenerative and inflammatory changes at the dermal-epidermal junction, including hemostasis, thrombosis, and necrosis; b) sinking of the distal phalanx in the claw capsule; and c) compression of the corium and epidermis, resulting in claw horn lesions such as solar hemorrhages, solar ulcers, double soles, and white line disease (Vermunt, 2007). However, results from recent studies have seriously challenged these assumptions. Although arterio-venous shunts in the bovine claw have been described (Vermunt and Leach, 1992), histopathological studies have shown that bovine laminitis can occur without the apparent pathological changes in the lamellae as described in equine laminitis (Lischer et al., 2002). This implies that not only the etiology, but also the name of the condition might be inappropriate, as no inflammatory process in the lamellae is necessarily present. Accordingly, the term claw horn disruption has been proposed for this condition (Vermunt, 2007). Nevertheless, throughout this paper we will conservatively refer to the condition described above as laminitis, and to the group of associated lesions as claw horn lesions.

Although the etiology of bovine laminitis is most probably multifactorial, its main cause is considered to be SARA (Kleen et al., 2003; Enemark, 2008). Subacute ruminal acidosis is defined as a ruminal fermentation malfunction leading to a drop in ruminal $\mathrm{pH}$ for various periods of time (Kleen et al., 2003). Subacute ruminal acidosis has also been associated with milk fat depression (MFD; Plaizier et al., 2008), although recent research has shown that the association is not 
straightforward. Apparently, SARA might lead to MFD only in the presence of other factors present in the rumen, such as polyunsaturated fatty acids (Sæbø et al., 2005; Perfield II et al., 2007; AlZahal et al., 2009). It might also be possible that rather than a causal relationship, the 2 are associated in that they arise under similar conditions (e.g., a lack of effective dietary fiber; Kleen et al., 2003). Given the associations between the 3 entities, SARA, MFD, and laminitis, we postulated that milk fat percentage in cows with claw horn lesions might be altered compared with that in cows without claw horn lesions. Particularly, we aimed to investigate whether cows diagnosed with claw horn lesions during routine claw trimming had a lesser milk fat percentage on test days preceding the diagnosis, compared with cows without these lesions.

\section{MATERIALS AND METHODS}

\section{Study Design and Population}

The study was designed as a retrospective cohort study and was conducted in a convenience sample of 11 typical Israeli commercial dairy farms from different geographical areas in Israel. Farms were members of the Israel Cattle Breeders Association (ICBA) and performed monthly milk recordings. Herd size ranged from 293 to 611 cows. The study population consisted of Israeli Holstein cows held under zero grazing in open sheds in 8 farms, and in freestall barns in 3 farms. All farms fed a TMR fed in ad libitum amounts and carried out a biannual routine claw trimming performed by the same professional claw trimmer between March and November 2007. The claw trimmer was trained 10 yr ago by the first author and has worked as a full-time professional claw trimmer ever since. Prior to data collection, the claw trimmer met with the first author to ensure uniform identification and recording of the claw lesions used in the study. During this meeting, claw lesions were discussed using photographs of affected claws. Data collected during routine claw trimmings were recorded to predefined forms and included date of trimming, cow number, leg on which the lesion occurred (e.g., hind left leg), and type of lesion (i.e., diagnosis). Data were collected from both the lactating and the dry cows. These data were entered into a spreadsheet and merged with test-day data that were retrieved from the ICBA central computer.

\section{Case Definition}

According to the claw lesions found during the routine herd trimming, cows were classified either as a case of laminitis or as a case of an infectious claw disease.
A case of laminitis was a cow diagnosed with at least one of the following claw horn lesions: double sole, solar ulcer, solar hemorrhage, white line disease, and solar abscess (Nordlund et al., 2004). A case of an infectious claw disease was a cow diagnosed with either digital dermatitis or interdigital dermatitis, or both. In 4 cows, both claw horn lesions and infectious claw diseases were found and these cows were classified as cases of laminitis. Tyloma was diagnosed in 8 cows, but due to its unclear etiology, was not classified as a case of laminitis or as a case of an infectious claw disease.

\section{Data Editing and Statistical Analyses}

All data editing and analyses were performed using SAS version 9.2 (SAS Institute, 2006). Results were considered to be of statistical significance if the relevant $P$-value was $<0.05$.

Milk Fat Percentage. Average test-day milk fat percentage was estimated from monthly test-day data using a mixed model with a marginal effect to account for repeated measurements from the same cow. Prior to modeling, test-day fat percentage was plotted against months in lactation in cows without laminitis to determine the relationship between the 2 variables (data not shown). A U-shaped relationship was found and, accordingly, stage of lactation was divided into 3 categories: mo 0 to 1 , mo 2 to 5 , and mo 6 to 10 . Parity number was grouped into 2 categories: first parity, and second and greater parity. Farm was modeled as a random intercept effect and the correlation matrix used for $\mathbf{R}$ was compound symmetry. The model we used was

$$
\mathrm{Y}=\text { parity (2 index variables) }
$$

+ LST (3 index variables) + I (8 index variables)

+ SUMMER (2 index variables) + LAM (2 index

$$
\text { variables })+\mathrm{I} \cdot \mathrm{LAM}+\mathrm{MILK}+\text { farm }(\text { random })+e \text {, }
$$

where $\mathrm{Y}$ is test-day fat percentage, LST is stage of lactation, I is time unit in months from a preceding test day to the diagnosis of the claw lesion (e.g., $1=$ test day 1 mo before diagnosis, $2=$ test day 2 mo before diagnosis), SUMMER is a dichotomous variable set to 1 if a test day occurred in the months from June to September and set to 0 if not, LAM is laminitis, MILK is test-day milk production $(\mathrm{kg})$ and $e$ a complex error term representing the within-cow correlation of testday fat percentage and the residual error. Significance of the fixed effects was determined using the $F$-test (PROC MIXED; SAS Institute, 2006). The fraction of variance in test-day milk fat percentage that could be attributed to farm variability was quantified from the 
Table 1. Diagnoses made by a professional hoof trimmer during routine trimming on 11 commercial dairy farms

\begin{tabular}{lcc}
\hline Diagnosis & Frequency & Percent \\
\hline No lesion present & 4,007 & 91.5 \\
Digital dermatitis & 146 & 3.3 \\
Interdigital dermatitis $^{\text {Tyloma }}$ & 23 & 0.5 \\
Double sole $^{1}$ & 8 & 0.2 \\
Solar ulcer $^{1}$ & 151 & 3.5 \\
Solar hemorrhage $^{1}$ & 34 & 0.8 \\
White line disease $^{1}$ & 6 & 0.1 \\
Solar abscess $^{1}$ & 2 & 0.1 \\
Lame, no diagnosis $^{\text {Total }}$ & 2 & 0.1 \\
\hline
\end{tabular}

${ }^{1}$ Lesions considered to be associated with laminitis.

variance components estimated from the model, using the following formula:

$$
\text { Fraction of variance at farm level }=\frac{\sigma_{h}^{2}}{\sigma^{2}+\sigma_{h}^{2}},
$$

where $\sigma_{h}^{2}$ is the variance between herds and $\sigma^{2}$ is the error variance (Dohoo et al., 2003). Finally, the random intercepts from the mixed model were plotted against the values of farm-level incidence of claw horn lesions for the purpose of investigating possible associations between the latter and a decreased milk fat percentage at farm level.

\section{RESULTS}

Data from 4,381 cows were included in the analysis. Of these, $372(8.5 \%)$ were diagnosed with at least one claw lesion on at least one claw (Table 1). One hundred ninety-five $(4.4 \%)$ cows were classified as cases of laminitis and 169 cows (3.9\%) were classified as cases of infectious claw disease. Double sole was the most common claw horn lesion (151 cows, 3.4\%) whereas digital dermatitis was the most common infectious claw disease (146 cows, 3.3\%). Farm-level prevalence of cows with lesions during the biannual routine trimming varied from 3.1 to 19.8 per 100 cows. The distribution of the different claw lesions over the participating farms is presented in Table 2 .

Test-day fat percentage was $0.05 \%$ less $(P<0.001)$ in first-parity cows compared with cows of greater parity and adjusted for all other variables in the model (Table 3). Compared with test-day fat percentage in mo 6 to 10 of lactation, test-day fat in mo 0 to 1 of lactation and in mo 2 to 5 of lactation were $0.25 \%$ greater $(P<0.001)$ and $0.06 \%$ less $(P<0.001)$, respectively. No difference was found in test-day fat percentage between cows with no claw lesions and cows classified as cases of infectious claw disease (data not shown). Therefore, test-day milk fat data of these 2 categories were grouped and compared with those of cases of laminitis. Estimated milk fat percentage of cows classified as cases of laminitis on the day of claw trimming was $0.17(P<0.012), 0.22(P=0.001)$, and $0.13 \%(P=0.058)$ less than that of cows with either no claw lesion or those with an infectious claw disease, on test days occurring 2,5 , and 6 mo before claw trimming, respectively (Table 3). Least squares means of test-day fat percentage are presented in Figure 1. The fraction of variance of test-day milk fat that could be attributed to farm variability was $8.5 \%$. Although a linear relationship between the value of the random intercept and the incidence of claw horn lesions was not evident (Figure 2), the farm with the smallest value for intercept $(-0.32)$ was the farm with the greatest prevalence $(15.68 \%)$ of claw horn lesions.

\section{DISCUSSION}

Overall prevalence of the claw lesions found in this study was relatively low compared with other studies. Philipot et al. (1994) found a prevalence of hoof lesions of $89 \%$ in cows from 160 French dairy farms, Vaarst et al. (1998) found claw lesions in $37 \%$ of the cows trimmed

Table 2. Number (\%) of cows diagnosed with claw lesions during routine claw trimming, stratified by farm

\begin{tabular}{lcrcc}
\hline Farm & Laminitis & Infectious & Any lesion & Total \\
\hline A & $12(4.1)$ & $21(7.2)$ & $34(11.6)$ & 293 \\
B & $61(15.7)$ & $16(4.1)$ & $77(19.8)$ & 389 \\
C & $15(2.6)$ & $6(1.0)$ & $21(3.6)$ & 588 \\
D & $12(2.0)$ & $15(1.0)$ & $19(3.1)$ & 611 \\
E & $9(2.7)$ & $3(0.7)$ & $24(7.2)$ & 335 \\
F & $23(5.2)$ & $35(11.7)$ & $28(6.3)$ & 444 \\
G & $10(3.4)$ & $9(3.0)$ & $46(15.4)$ & 298 \\
H & $18(6.0)$ & $2(10.9)$ & $27(9.0)$ & 300 \\
I & $13(2.7)$ & $2(0.6)$ & $13(13.8)$ & 477 \\
J & $11(3.5)$ & $171(3.9)$ & $19(5.8)$ & 316 \\
K & $11(3.3)$ & & $374(8.5)$ & 330 \\
Total & $195(4.4)$ & & & 4,381 \\
\hline
\end{tabular}




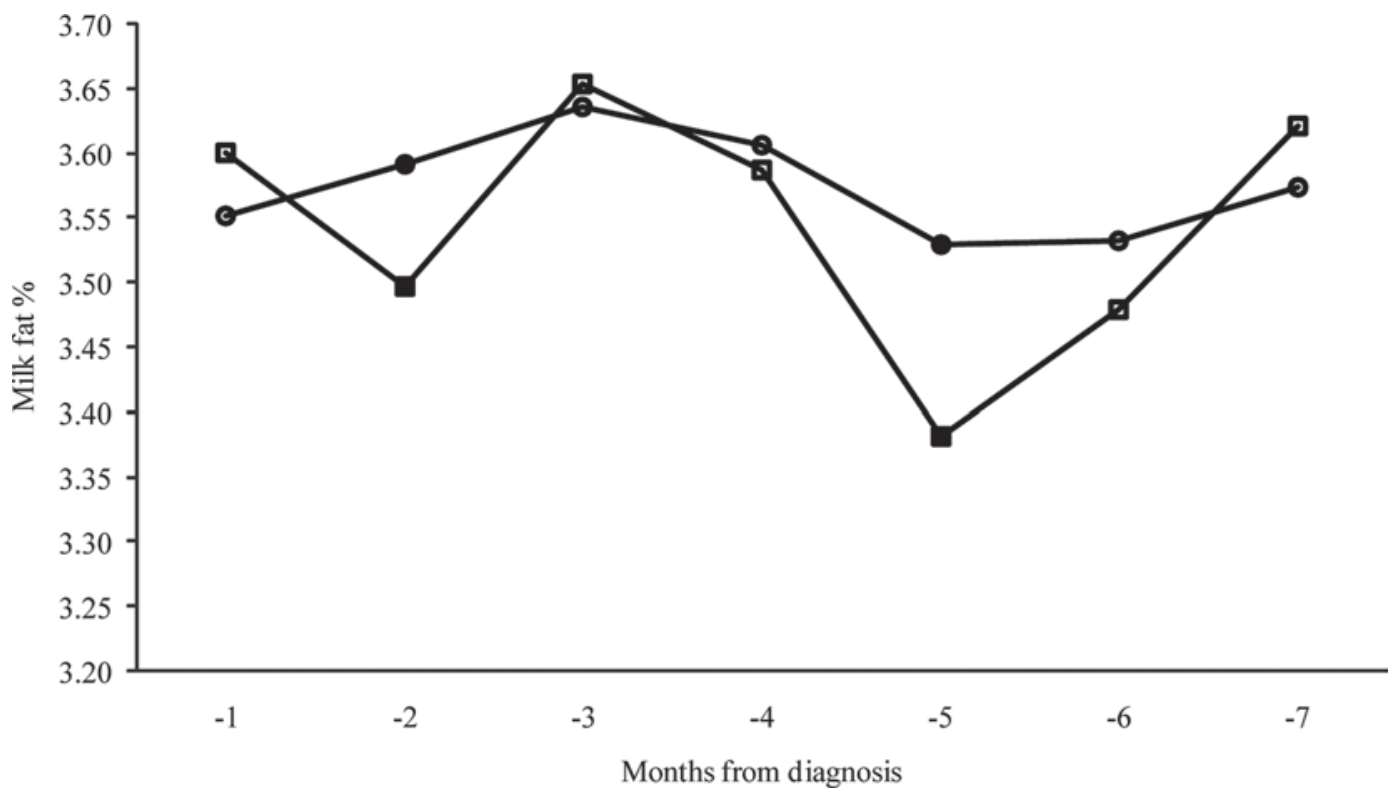

Figure 1. Least squares means of test-day milk fat percentage in months preceding a routine claw trimming on which cows were either diagnosed with a claw horn lesion $(\square)$ or without $(\bigcirc)$. Filled squares and circles indicate significant differences $(P<0.05)$, open squares indicate no significant difference $(P>0.05)$.

in a Danish study, and Manske et al. (2002) found an overall prevalence of $72 \%$ for claw lesions in a study comprising 101 Swedish dairy farms. These differences are most probably due to differences in management, feeding, type of lesions recorded, and study objectives. In our study, only 3 farms housed cows in freestalls, whereas the remaining 8 farms used dried manure bedding. The relatively small proportion of cows kept on cement floors could explain the lower prevalence of claw lesions in our study, as this floor type has been associated with a greater risk for claw lesions (Somers et al., 2005a,b).

Table 3. Association between various variables and milk fat percentage, $P$-value and $95 \%$ confidence interval estimated from a linear mixed model with a random farm effect and marginal effect for repeated measurements

\begin{tabular}{|c|c|c|c|}
\hline Variable & Milk fat ${ }^{1}(\%)$ & $P$-value & $95 \% \mathrm{CI}$ \\
\hline \multicolumn{4}{|l|}{ Parity } \\
\hline 1 & -0.05 & $<0.001$ & $(-0.08,-0.02)$ \\
\hline$>1$ & 0 & & \\
\hline \multicolumn{4}{|l|}{ Stage of lactation } \\
\hline $0-1 \mathrm{mo}$ & 0.25 & $<0.001$ & $(0.22,0.27)$ \\
\hline $2-5 \mathrm{mo}$ & -0.06 & $<0.001$ & $(-0.08,-0.04)$ \\
\hline $6-10 \mathrm{mo}$ & 0 & & \\
\hline \multicolumn{4}{|l|}{ Laminitis.months from trimming } \\
\hline No laminitis.1 mo before trimming & 0.03 & 0.677 & $(-0.11,0.17)$ \\
\hline No laminitis 2 mo before trimming & 0.17 & 0.012 & $(0.04,0.31)$ \\
\hline No laminitis 3 mo before trimming & 0.06 & 0.384 & $(-0.07,0.19)$ \\
\hline No laminitis 4 mo before trimming & 0.10 & 0.150 & $(-0.03,0.23)$ \\
\hline No laminitis. 5 mo before trimming & 0.22 & 0.001 & $(0.09,0.36)$ \\
\hline No laminitis. 6 mo before trimming & 0.13 & 0.058 & $(0.00,0.27)$ \\
\hline No laminitis. 7 mo before trimming & 0.03 & 0.668 & $(-0.10,0.16)$ \\
\hline No laminitis. 8 mo before trimming & 0 & & \\
\hline Laminitis. 1 mo before trimming & 0 & & \\
\hline Laminitis. 2 mo before trimming & 0 & & \\
\hline Laminitis 3 mo before trimming & 0 & & \\
\hline Laminitis. 4 mo before trimming & 0 & & \\
\hline Laminitis. 5 mo before trimming & 0 & & \\
\hline Laminitis. 6 mo before trimming & 0 & & \\
\hline Laminitis. 7 mo before trimming & 0 & & \\
\hline Laminitis. 8 mo before trimming & 0 & & \\
\hline
\end{tabular}

${ }^{1}$ Adjusted for farm, test-day milk production $(\mathrm{kg})$, and summer months. 


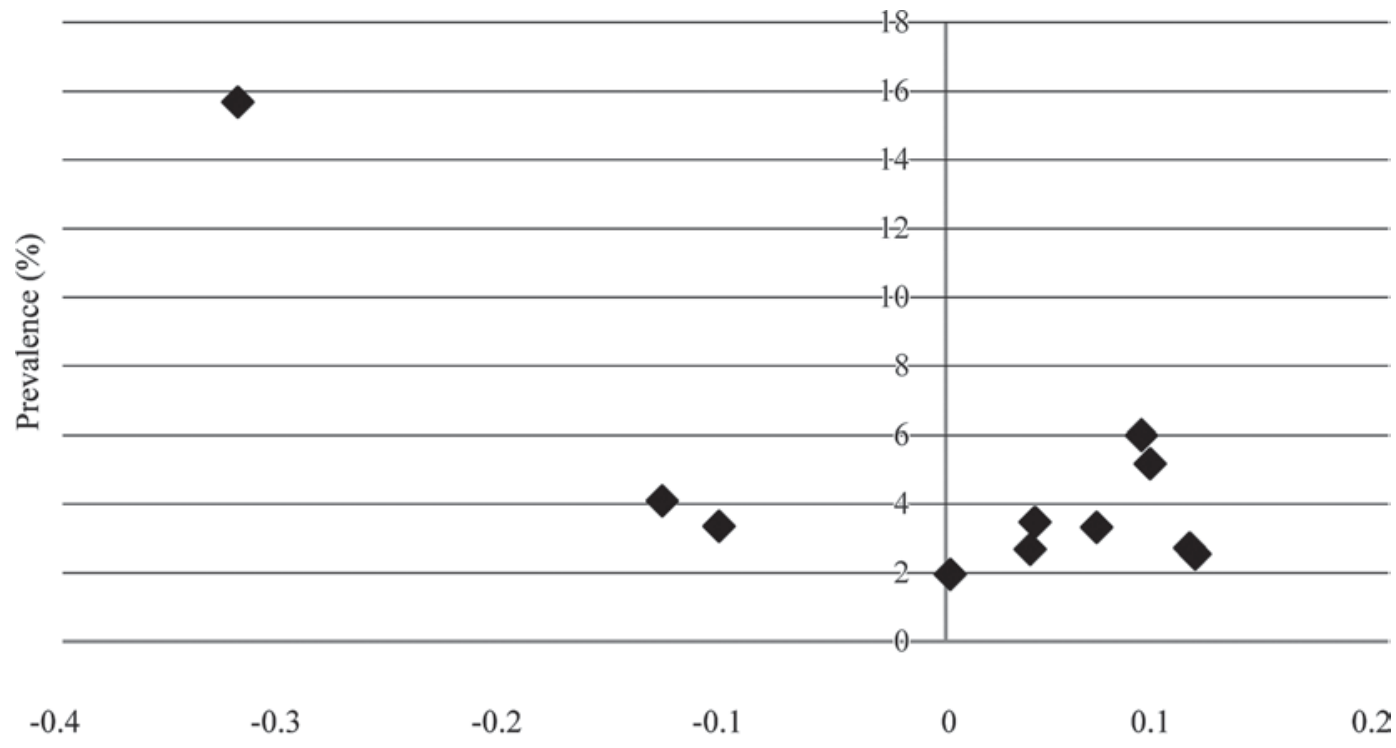

Random intercept value (test-day milk fat \%)

Figure 2. Relationship between farm-level prevalence of claw horn lesions and the random farm effect for milk fat percentage obtained from a linear mixed model.

The greatest differences in test-day milk fat between cows with claw horn lesions and those without (Figure 1) were found on test days 2 and 5 mo before routine hoof trimmings. The bovine wall hoof horn has been estimated to grow at a rate of approximately $5 \mathrm{~mm}$ per mo (Dyce and Wensing, 1983; Telezhenko et al., 2009). If sole horn grows at a comparable rate, this would imply that many lesions would become apparent on the sole surface 1 to 2 mo after onset and could explain the difference in milk fat percentage found on test days occurring 2 mo before routine claw trimming. The difference in milk fat percentage found on test day 5 mo before routine hoof trimming is less understandable; it could indicate that certain cows are more prone to experience (repeated) events of SARA. In fact, individual variation in ability to cope with dietary factors that predispose to SARA has been demonstrated (Schwartzkopf-Genswein et al., 2003; Dohme et al., 2008). However, it must be kept in mind that the retrospective character and the relatively infrequent hoof trimmings in this study do not allow a good estimation of the time of onset of the claw lesions found.

Our cow-level findings support the clinical distinction between claw horn lesions and those related to infectious diseases. The claw trimmer, blind to the test-day results of cows that were trimmed, identified 2 populations (i.e., cows with claw horn lesions and cows without) with significant differences in test-day milk fat percentage.
Our herd-level findings support the possible use of test-day milk fat percentage as a tool for identifying herds at risk for claw horn lesions. Farm-level variability accounted for $8.5 \%$ of the total variance in test-day milk fat percentage, and in all but one farm, random intercept values estimated from our model varied from -0.13 to 0.11 . The corresponding claw horn lesion prevalence on these farms was between 1.96 and $6.00 \%$ (Figure 2). However, the one farm with the extreme random intercept value of -0.32 was also the farm with the greatest claw horn lesion prevalence of $15.68 \%$. Thus, test-day data might be useful as a screening test for identifying farms at risk for laminitis.

To the best of our knowledge, decreased test-day milk fat percentage in dairy cows diagnosed with claw horn lesions has not been described. A decreased milk fat percentage has, however, been associated with SARA, and a prevalence of $10 \%$ or greater of cows with a milk fat percentage of 2.5 or less has been suggested as indicative of a SARA-problem in a Holstein herd (Nordlund and Garret, 1994; Garret, 1996). Subacute ruminal acidosis has also been associated with laminitis, and various researchers have asserted that the latter is the most significant sequel of SARA (Ivany et al., 2002; Cook et al., 2004). Based on these associations, it is plausible that SARA played a role in the association we found, being associated with both a decreased milk fat percentage and claw horn lesions. A prospective study with a greater frequency of claw examinations would be 
necessary to help clarify these associations. Our findings indicate that test-day milk fat might be useful as a tool for monitoring cows and farms at risk for claw horn lesions.

\section{ACKNOWLEDGMENTS}

The authors thank the Israel Dairy Board (Yehud, Israel) for funding this work.

\section{REFERENCES}

AlZahal, O., M. M. Or-Rashid, S. L. Greenwood, M. S. Douglas, and B. W. McBride. 2009. The effect of dietary fiber level on milk fat concentration and fatty acid profile of cows fed diets containing low levels of polyunsaturated fatty acids. J. Dairy Sci. 92:11081116 .

Cook, N. B., K. V. Nordlund, and G. R. Oetzel. 2004. Environmental influences on claw horn lesions associated with laminitis and subacute ruminal acidosis in dairy cows. J. Dairy Sci. 87:(E. Suppl.):E36-E46.

Dohme, F., T. J. DeVries, and K. A. Beauchemin. 2008. Repeated ruminal acidosis challenges in lactating dairy cows at high and low risk for developing acidosis: Ruminal pH. J. Dairy Sci. 91:35543567.

Dohoo, I. R., W. Martin, and H. Stryhn. 2003. Veterinary Epidemiologic Research. University of Prince Edward Island, Charlottetown, Prince Edward Island, Canada.

Dyce, K. M., and C. J. G. Wensing. 1983. Anatomie van het rund. Bohn, Scheltema \& Holkema, Utrecht, the Netherlands.

Enemark, J. M. D. 2008. The monitoring, prevention and treatment of sub-acute ruminal acidosis (SARA): A review. Vet. J. 176:3243.

Garrett, E. F. 1996. Subacute rumen acidosis. Large Anim. Vet. 11:6-10.

Ivany, J. M., D. M. Rings, and D. E. Anderson. 2002. Reticuloruminal disturbances in the bovine. Bovine Pract. 36:56-64.

Kleen, J. L., G. A. Hooijer, J. Rehage, and J. P. T. M. Noordhuizen. 2003. Subacute ruminal acidosis (SARA): A review. J. Vet. Med. A Physiol. Pathol. Clin. Med. 50:406-414.

Lischer, Ch. J., P. Ossent, M. Räber, and H. Geyer. 2002. Suspensory structures and supporting tissues of the third phalanx of cows and their relevance to the development of typical sole ulcers (Rusterholz ulcers). Vet. Rec. 151:694-698.

Manske, T., J. Hultgren, and C. Bergsten. 2002. Prevalence and interrelationships of hoof lesions and lameness in Swedish dairy cows. Prev. Vet. Med. 54:247-263.
Nordlund, K. V., N. B. Cook, and G. R. Oetzel. 2004. Investigation strategies for laminitis problem derds. J. Dairy Sci. 87:(E. Suppl.):E27-E35.

Nordlund, K. V., and E. F. Garrett. 1994. Rumenocentesis: A technique for collecting rumen fluid for the diagnosis of subacute rumen acidosis in dairy herds. Bovine Pract. 28:109-112.

Perfield, J. W. II, A. L. Lock, J. M. Griinari, A. Sæbø, P. Delmonte, D. A. Dwyer, and D. E. Bauman. 2007. Trans-9, cis-11 conjugated linoleic acid reduces milk fat synthesis in lactating dairy cows. J. Dairy Sci. 90:2211-2218.

Philipot, J. M., P. Pluvinage, and F. Luquet. 1994. Clinical characterization of a syndrome by ecopathology methods: An example of dairy cow lameness. Vet. Res. 25:239-243.

Plaizier, J. C., D. O. Krause, G. N. Gozho, and B. W. McBride. 2008. Subacute ruminal acidosis in dairy cows: The physiological causes, incidence and consequences. Vet. J. 176:21-31.

Sæbø, A., P.-C. Sæbø, J. M. Griinari, and K. J. Shingfield. 2005. Effect of abomasal infusions of geometric isomers of 10.12 conjugated linoleic acid on milk fat synthesis in dairy cows. Lipids 40:823-832.

SAS Institute. 2006. User's Guide: Statistics. Version 9.1. SAS Institute, Cary, NC.

Schwartzkopf-Genswein, K. S., K. A. Beauchemin, D. J. Gibb, D. H. Crews Jr., D. D. Hickman, M. Streeter, and T. A. McAllister. 2003. Effect of bunk management on feeding behavior, ruminal acidosis and performance of feedlot cattle: A review. J. Anim. Sci. 81:E149-E158.

Somers, J. G. C. J., K. Frankena, E. N. Noordhuizen-Stassen, and J. H. M. Metz. 2005a. Risk factors for digital dermatitis in dairy cows kept in cubicle houses in the Netherlands. Prev. Vet. Med. 71:11-21.

Somers, J. G. C. J., K. Frankena, E. N. Noordhuizen-Stassen, and J. H. M. Metz. 2005b. Risk factors for interdigital dermatitis and heel erosion in dairy cows kept in cubicle houses in the Netherlands. Prev. Vet. Med. 71:23-34.

Telezhenko, E., C. Bergsten, M. Magnusson, and C. Nilsson. 2009. Effect of different flooring systems on claw conformation of dairy cows. J. Dairy Sci. 92:2625-2633.

Vaarst, M., J. Hindhede, and C. Enevoldsen. 1998. Sole disorders in conventionally managed and organic dairy herds using different housing systems. J. Dairy Res. 65:175-186.

Vermunt, J. J. 2007. One step closer to unravelling the pathophysiology of claw horn disruption: For the sake of the cows' welfare. Vet. J. $174: 219-220$.

Vermunt, J. J., and D. H. Leach. 1992. A scanning electron microscopic study of the vascular system of the bovine hind limb claw. N.Z. Vet. J. 40:146-154. 